\title{
The Superintendent of Documents and American Libraries: A Liaison Approach
}

$A^{\text {common base of interests and opera- }}$ library related enterprises in the United States: the work of the Superintendent of Documents ${ }^{1}$ and the card distribution of the Library of Congress. Both maintain sales and distribution programs which run into millions of items at an annual income which measures up to that of a major industrial or business corporation; they serve a similar clientele-libraries, individuals, cultural and research agencies, scholars; in the final analysis, both are expected to provide the key which will unlock the resources of libraries-whether such key be a catalog entry, an index, a list, a bibliography, or other aid. The economies in cataloging and the services of many libraries have, in large measure, become dependent upon these two central enterprises of the federal government. Other significant features of identity exist in the internal mechanism of each agency, as evidenced in a recent comparative job analysis and positionclassification survey made by the author. Incidentally, both face the same hazards of annual requests for appropriations before Congress-with the same difficulties in planning long-range development and the same pressures inherent in a contracting economy in federal expenditures.

1 The popularized term "Superintendent of Docu. ments" will be used in this paper rather than the official title, Division of Public Documents of the Government Printing Office.
The cumulative advantage of having managed the latter enterprise, firsthand knowledge of some of the internal problems of the office of the Superintendent of Documents, and cognizance of some of the needs in processing documents prompts me to present this approach to the problemnamely, the liaison approach.

\section{The Background}

The literature of the A.L.A. Public Documents Committee from 1934 to 1938 and allied contributions to the subject in the journals since that date provide adequate orientation for the interested student of the field. By taking off, then, from Mr. Wilcox's 1944 contribution ${ }^{2}$ as the most comprehensive statement of the problem because it incorporates the view of more than one hundred depository libraries, it is now necessary to review some of the significant history since that year. In their greater or lesser impact upon the problem, nevertheless, here follow some pertinent events of recent date:

I. Joint A.L.A.-A.C.R.L. effort in developing the Documents Expediting Project operating centrally from Washington, D.C. with its prime objective to procure for libraries such documents which are not distributed normally by the Superintendent of Documents or which are difficult to obtain through the usual channels

2 Wilcox, Jerome K. "Indexing and Distribution of Federal Publications: A Program for Action." $L_{i-}$ brary Journal 69:1029-32, Dec. I, 1944. 
2. Declassification of a large collection of documents which were "restricted" or otherwise designated as confidential matter during and shortly after the war years. This is estimated to require about two years' work in the office of the Superintendent of Documents to process these documents

3. Cumulative Catalog of the Library of Congress printed cards-a new development in keeping current the monumental Edward Brothers edition of the Catalog of Books in the Library of Congress Represented by L.C. Cards. The immediate subscriptions (more than 600) attest to its role as a cataloging and bibliographic aid. The May issue, for example, lists more than 400 entries for U.S. documents

4. College and university enrolments have swelled to unprecedented figures in the past two years. Greater library resources are needed to meet the demands of this new mature student seeking practical answers to the socio-economic and technological problems of contemporary American life. Government publications represent some of the richest source materials for college and university libraries. Inadequacies of staff to service the documents collection, weaknesses of the Monthly Catalog as an index to documents, and the six-year lag in publishing the Documents Catalog are handicaps

5. A revised code of rules for descriptive cataloging has recently been prepared and published by the Library of Congress. Its effect upon rapid and probably more intelligible cataloging of documents should be beneficial

6. A new area of interest faces the documents librarian in research libraries in the acquisition, processing, and reference use of United Nations and related documentsthereby enlarging the field of documents activity

7. Personnel changes-a new Superintendent of Documents, Fred W. Cromwell, ably assisted by the Assistant Superintendent of Documents, Roy B. Eastin. Persons, often more than events, may be more instrumental in shaping improved liaison with American libraries

8. A political shift has brought into power a new Congress with curtailment of federal expenditures as one of its avowed objectives. The Superintendent of Documents and other offices of the Government Printing Office, not unlike other agencies, may expect a similar fate

9. Problems facing the Superintendent of Documents: cataloging and distributing the mass of declassified documents recently inherited; speed and more speed in delivery of the depository sets to libraries and in the sale of currently publicized documents; promptness in preparing and distributing the Monthly Catalog; improved entry leading to desirable conformity with established cataloging form; limited budgetary appropriations and the urgency of many immediate and longrange jobs to be done; etc.

I0. Liquidation of the Documents Catalog

I I. Conferences on principles and methods of securing bibliographic control over governmental reports of scientific and technical nature

I2. The Wilcox survey and recommendations in the summer of 1947.

This is a realistic inventory. There is needed a comprehension of and sensitivity to these developments in appraising the job of the Superintendent of Documents in relation to our libraries. What is needed is an awareness of its management problems and recognition that what is to be accomplished can only be accomplished through joint effort. Traditional criticisms aimed at the Superintendent of Documents will be misdirected and fruitless. Such criticism is certainly not a constructive answer to an agency which has experienced a 40 per cent increase in work load but has received no increased appropriations to parallel this growth.

\section{Persistence of the Basic Weakness}

Among the developments there is reserved for special mention the recent Wilcox report. ${ }^{3}$ The report warrants specific mention not only because of its recommendations for technical and operational improvements but also as a significant step

${ }^{8}$ U. S. Supt. of Documents. Monthly Catalog ... No. 632, September 1947 , p. iii-vi. 
in promoting relations between the Superintendent of Documents and the library profession through the appropriate A.L.A. committee. For the details of the report, analysis, recommendations, and resultant changes one must consult the September I 947 issue of the Monthly Catalog and the recent announcement in the Library Journal. ${ }^{4}$ The modifications and changes have been all to the good. The proposed supplements will be particularly gratifying and helpful to documents users. Despite the incorporation of these sound recommendations and worth-while new features, there still persist the following weaknesses of the Monthly Catalog:

I. General absence of added personal name entries which, in effect, are true author entries under government sponsorship and support: contributors, researchers, specialists, and others responsible for the authorship of many government publications

2. Inadequate subject cataloging treatment in the accepted sense

3. Descriptive cataloging inconsistent with established descriptive cataloging rules

4. Absence of a dictionary arrangement of author, title, subject, and cross-reference entries.

For lack of a dictionary arrangement, for example, the entries on housing, in the improved September issue of the Monthly Catalog, are dispersed over some 18 different pages. Incidentally, for the 95 pages of entries in this issue there was required an index which ran over into more than 30 pages. Were the index pages prepared in the same type size as the entries in the text, the result would be even more disproportionate. This deficiency, notably now that the Documents Catalog will no longer be issued, remains a sore spot in terms of bibliographic facility and use of the indexes.

While the availability of L.C. cards for U.S. documents assists many libraries in their cataloging problems, this service itself

${ }^{4}$ Library Journal 72:1254, Sept. 15, 1947. is insufficient in many respects. It is only selective; the service is slow; L.C. is often incapable of meeting commitments of preassigned L.C. card numbers in the Monthly Catalog.

Some of these weaknesses, particularly the dictionary arrangement, has been compensated for in the past through the biennial Documents Catalog. Unfortunately, the economy ax and shifts in work priorities resulted in liquidation of the Documents Catalog. It is only necessary, then, to reread Ruth M. Erlandson's observations ${ }^{5}$ regarding documents cataloging policy and practices to realize that it is later than we think. Questions relating to organization of documents-selective versus full cataloging, subject approach, classification systems, training of documents librarians, etc.-are no longer academic. They are as real as the serious library service deficiencies which germinate from them.

\section{The Proposal}

It is proposed that there be published one master bibliographic tool, therefore, which would represent a fusion of the features of the present Monthly Catalog and the former Documents Catalog with several new features. The Printing Act of 1895 (28 U.S. Stat. 6oI-24) provides for the preparation and publication of a monthly catalog and a comprehensive index. The language of the act, however, does not set forth the specifications as to format of the catalog or as to the character of the index. It follows, therefore, that the "catalog" and the "index" could be merged into one and the final product would conform with the letter and spirit of the law.

The following outline indicates some of the features of the proposal:

Title: Federal Documents Catalog.

Date: beginning Jan. I, 1949.

- Boyd, Anne M. United States Government Publi cations. N.Y., H. W. Wilson Company, 1941, p. 5 10-18, Appendix B. 
Frequency: monthly.

Cumulations: quarterly; annual; $5 \mathrm{yr}$. cumulation; io yr. cumulation.

Format: page setup similar to that used in the L.C. Cumulative Catalog.

Arrangement: dictionary arrangement of main, subject, title, added personal names, and cross-reference entries. History cards to be included as a separate and appended feature. (In short, a complete dictionary index which will serve for documents as the C.B.I. now serves for books.)

Characteristics of the entry: standard descriptive cataloging form according to the new code of the Library of Congress; all tracings; three classification symbols: Superintendent of Documents symbol; L.C. class number; Dewey class number; price of the publication; asterisk denoting publications sent to depositories.

Source: cataloging of the publications to be done centrally in the Library Section of the office of the Superintendent of Docu- ments. May be helped via the cooperative cataloging route by other federal agencies, as may be necessary or desirable.

Scope: all federal documents. (Private laws, public laws, House reports, Senate reports, etc., would not be cataloged. These would be listed, as at the present time, and appended as a separate listing.)

Price: since such a publication is especially designed for libraries and would be beyond the normal operating funds and personnel for its systematic preparation in the office of the Superintendent of Documents, it would necessarily have to be maintained on a self-sustaining basis by the subscribers. Price to be established on cost plus 5 per cent basis and will depend, of course, upon the number of subscribers. Annual subscription fee. No free distribution to depositories or other federal agencies-strictly on a self-sustaining basis.

The characteristics of the proposed entry are suggested in the chart below.

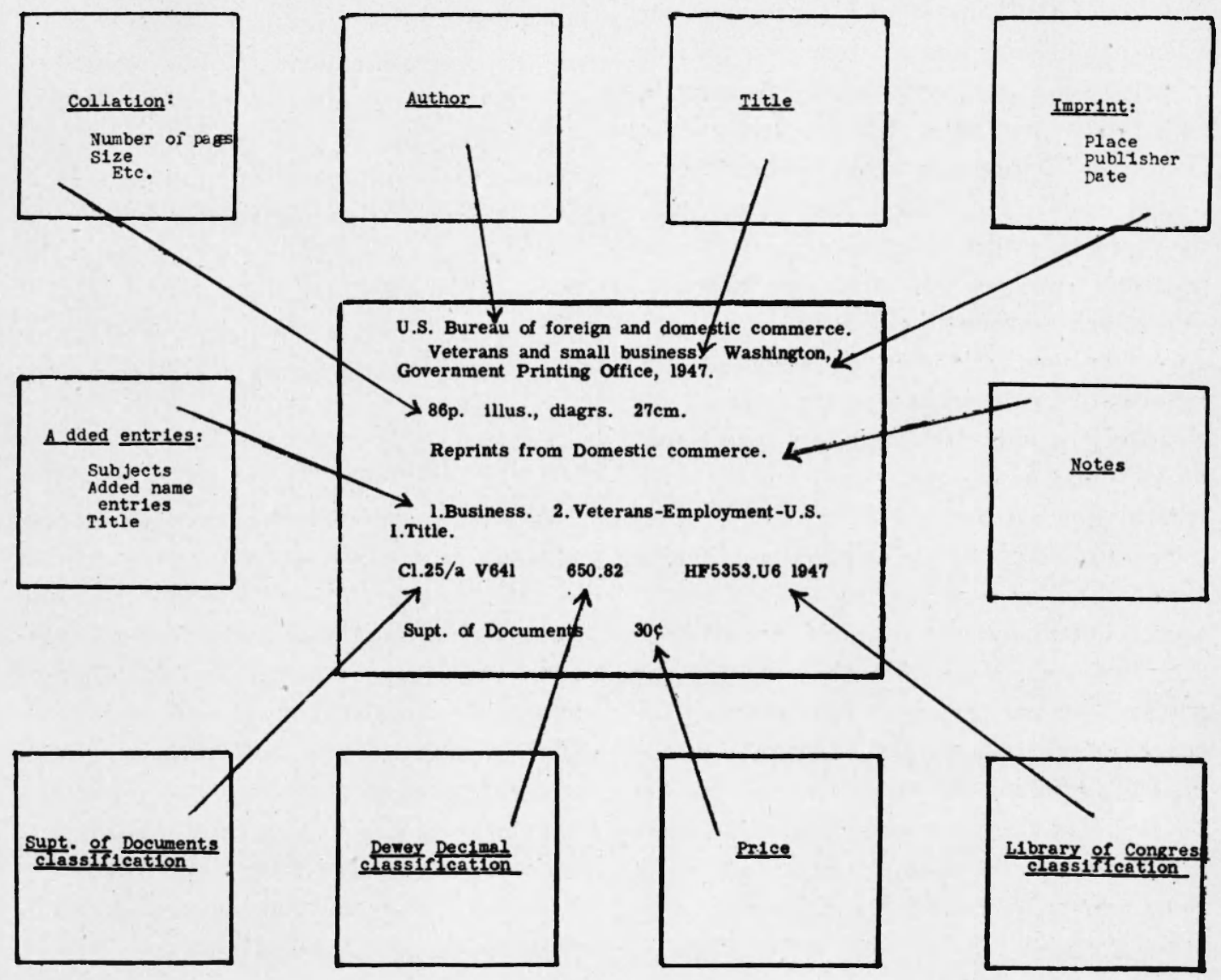


Perhaps the strongest statement in defense of the proposed project, as outlined, is to be found in the very fundamentals on which it rests. Primarily, this is not just another bibliographic tool. It would actually be used as the catalog of the holdings of every depository library. This is its principal justification. It is tailored cataloging for documents depositories. In this sense, it is strikingly different from the L.C. Cumulative Catalog which describes only the collection of the Library of Congress but serves as a cataloging and bibliographic aid for other research libraries. Furthermore, the recipients of the proposed federal documents catalog would have greater assurance of receiving as full coverage as possible of all government publications since the catalog will emanate from the office of the Superintendent of Documents. The card distribution service or the Cumulative Catalog of the Library of Congress, on the other hand, is limited in that both provide only for such documents received, selected, and finally cataloged by the Library of Congress. More significantly-being concerned exclusively with federal documents, the Superintendent of Documents must promptly process all such publications. Were such a proposed catalog to stem from any other agency, it would be subject to the hazards of priorities which that agency inescapably would establish in processing books, journals, pamphlets, etc., along with federal documents.

Not only do libraries utilize the Monthly Catalog as an acquisitions and reference source but many have come to accept it as their informal type of author catalog for government publications. It is precisely because libraries regard the Monthly Catalog as an authoritative cataloging of federal publications that it should now take shape as a bona fide centralized cataloging product consistent with established rules and form for descriptive and subject cataloging.

\section{Some Fiscal and Staff Considerations}

An appropriate committee could study, in time for January 1949, the problems of production costs and determination of a fair subscription price to the federal documents catalog. It could also study the probable staff necessary to assure a competent product delivered on time. Preliminary studies indicate that the production cost, exclusive of salaries, would be about two-thirds that of a typical issue of the Cumulative Catalog of the Library of Congress. Inadequate data exist at this time as to more definite cost analysis. Catalog cards, similar to the L.C. card, for the entries would have to be prepared first by the Government Printing Office as the basis for photo-offset of the proposed page layout. Thus, there is the possible thought of the Superintendent of Documents selling catalog cards for federal publications as a by-product of this enterprise. It may or may not be feasible for the Superintendent of Documents to undertake a card sales venture for federal publications, but it is worthy of consideration by an appropriate committee. It is clear, however, that the more than 10,000 subscriptions to the Monthly Catalog at the present time should be a potent factor in keeping the subscription price for the proposed federal documents catalog reasonably low.

\section{Potential Advantages}

What are some of the potential advantages of centralized cataloging of federal documents and a master bibliographic tool in the form of a cumulative dictionary cata$\log$ ? Primarily, it bears the advantage of savings to libraries, in money and manpower, which accrue in any centralized cataloging scheme-provided it is run efficiently, economically, and with a quick professional responsiveness to consumer needs. Problems of catalog maintenance in libraries should be resolved, to some extent-relief of con- 
gested "U.S." catalog trays and of the congested patron traffic using this area of the library's main catalog; reduction or possible elimination of labor costs in filing L.C. cards for documents. Several subscriptions would place copies of the federal documents catalog in the main reference room, catalog division, departmental libraries, and other logical units in a large library, thereby spreading the service possibilities over a wider range and acquainting a larger library clientele with the availability and value of federal publications. Procurement of the federal documents catalog would render unnecessary further purchase of L.C. cards for government publications, thus realizing for the aggregate libraries which now catalog federal documents a savings of more than $\$ 30,000$ annually. Test studies have disclosed that the aggregate libraries now expend more than $\$ 30,000$ each year in the purchase of L.C. cards for documents. The Dewey class number would enable libraries which employ this classification system, but which order few L.C. cards for documents, to incorporate federal documents more easily in their classified collection of books on various subjects.

Government researchers and specialists in various fields, too, often neglected in bibliographic reference, would receive through full centralized cataloging their due recognition and publicity. Library patrons and students, familiar with the use of the Readers' Guide to Periodical Literature and other dictionary indexes, should find an easy transfer of skills in consulting the federal documents catalog for location of items. It would relieve reference librarians of much routine search. Readers advisory work should similarly be facilitated and strengthened. The element of memory, upon which many documents librarians have long been dependent, would no longer need to be a keynote in servicing documents collections. The orthodox issuing bureau ap- proach would be invaded, indeed, and would give way to the more significant subject approach to documents in academic and public libraries. By virtue of the alphabetical filing arrangement of entries, nevertheless, all works by a particular issuing bureau could easily be located. In a very real sense, it should be a major step in humanizing the field of documents and in gaining greater bibliographic control over federal publications.

There are disadvantages to be contended with, to be sure. And it is here that the importance of a competent committee is of the greatest significance. Questions such as these, among others, might well be raised : Would it not make for a bulky and uneconomical way in which to check the acquisition of items? What of incompatibility in subject headings with that used in other libraries? Would it be possible for the Superintendent of Documents to edit and publish this in sufficient time so that it would reach libraries promptly? Would it really augment reference service and be used widely by library patrons-or is this wishful thinking? Other and more critical queries may well be raised and investigated.

\section{The Road Ahead}

The efforts of Kuhlman, Boyd, Wilcox, Childs, Miller, Wyer, and others have represented a level of thinking and action for improved library service which merits a permanent place in American library development and control of the documents resources. The writings of the A.L.A. Public Documents Committee warrant rereading for an appreciation of the constructive literature toward effective Superintendent of Documents -American libraries liaison. Merritt's excellent study ${ }^{6}$ points

- Merritt, LeRoy C. The United States Government As Publisher. Chicago, University of Chicago Press, 1943. 
the way to more scientific analysis and fundamentals in government publications as a communication medium in American life and as a publishing venture in the realm of research and administration.

The future course should be one in which the Superintendent of Documents becomes increasingly conscious of libraries and their clientele as consumers and, in turn, libraries become increasingly aware of the resources and management problems of the office of the Superintendent of Documents. A cursory reading of the past two annual reports reveals sufficiently a picture of the managerial problems. In any event, several steps warrant attention in the road ahead. The office of the Superintendent of Documents is not merely a sales agency; it has great potentialities and should strive for a position of leadership in cataloging and bibliographical control of federal publications of all kinds. The subject approach must be exploited to the fullest. When it develops that funds and personnel are inadequate to maintain the balance of vast, free distribution and sales on the one hand and necessary bibliographic and indexing activities on the other, organized library opinion through the A.L.A. National Relations Office and through members of Congress should be mobilized well in advance of the appropriations deadline. Libraries should press for a change in legislation which would make it possible to obtain a liberal appropriation for travel by the Superintendent of Documents-for the purpose of visiting depositories, witnessing documents collections and librarians in action, and gaining first-hand knowledge of the importance of bibliographic and indexing aids in libraries.

We must impress deeply upon the Superintendent of Documents that, through the instrumentality of libraries, government publications are brought into the hands of scholars, technicians, researchers, subject specialists, and American library patrons as a whole. Large as the volume of sales by the Superintendent of Documents may be to private individuals it nevertheless represents but a small fraction of the larger clientele, actual and potential, reached through the medium of libraries. The pursuit for all processed publications must continue and a system of distribution perfected - a prime responsibility of the Superintendent of Documents and the successful achievement of which would greatly cement the relationship with American libraries. Major bibliographic or cataloging activities, for all practical purposes, appear to be possible only on a self-sustaining basis, as evidenced in the large library enterprises of the Library of Congress.

The quality of the relationship will depend upon the quality of understanding and good faith of the two parties.

\section{The Documents Expediting Project}

\section{(Continued from page I7)}

strated pragmatically that these materials are available to those libraries which are aggressive enough to go after them on a cooperative basis. Furthermore, with an economy-minded Congress and with printing costs mounting higher and higher, it may well be that libraries may have to rely more and more on the kind of service provided by a documents expediting office for the acquisition of government publications. To guarantee adequate distribution of the many publications now on hand the joint committee invites additional subscriptions to the Documents Expediting Project and assures every participant a substantial return on its investment. 